\title{
Human Capital, Social Capital and Economic Growth
}

\author{
By Weiqiu $Y u^{*}$
}

\begin{abstract}
Keeping track of the performance of a nation's economy and analyzing the factors that determine economic growth and its fluctuations are among the main objectives of economic research. This paper presents an analytical framework connecting human capital and social capital to economic growth. It adds to the existing literature in three areas. First, the existing literature focusing on a narrow definition of human capital misses some crucial aspects of human capital policy. This paper provides a broader framework to evaluate both economic and social policies on human capital. Second, while various economic and social indicators related to human capital exist in the literature there is not a comprehensive list of indicators for human capital only. The paper develops a set of such indicators for the purpose of monitoring economic growth and making comparisons across countries or regions. Finally, we identify policy channels through which human capital formation interacting with social capital can be for stronger economic growth.
\end{abstract}

\section{Introduction}

Keeping track of the performance of a nation's economy and analyzing the factors that determine economic growth and its fluctuations are among the main objectives of economic research. To that end, economists have developed a variety of indicators and indexes. The national income accounts provide quarterly data on output, income and expenditures by major sectors of the economy. Monthly publications by central banks contain details on all aspects of the monetary system. Special surveys provide monthly information on labor market conditions, producer, wholesale and retail prices. Other surveys track consumer confidence and business investment intentions. Up to the minute values of a variety of stock and bond markets are shown daily on television and can be found at any time through the internet.

Economic indicators monitor only one aspect of human activity. There are other dimensions of human experience which arise from interactions among a variety of individuals and groups. These other aspects of human activity are also monitored through a set of indicators called "social indicators". A main purpose of this group of indicators is to determine the extent to which economic growth translates into improvements in human conditions. They deal with the distribution of income, by providing data on income levels by

${ }^{*}$ Chair of Economics, Department of Economics, University of New Brunswick, Canada. 
different individuals and families which are used to develop measures of poverty, educational attainment, and the state of health - mortality rates, people covered by health insurance and the like. The United Nations Development Programme initiated in 1990 a publication which contains a selected grouping of a mixture of social and economic indicators called "human development indicators". The purpose of this publication, which has been updated annually, is to determine how the process of economic growth "translates - or fails to translate - into human development in various societies is defined as "the entire spectrum through which human capabilities are expanded and utilized" (p.iii).

The distinction between economic and social indicators parallels the separation of disciplines analyzing human behavior, where economics deals with choices about how people allocate time and other resources while disciplines such as sociology explore various aspects of the interaction among individuals and groups. This separation may sometimes be useful for analytical purposes, but masks the fact that human activity cannot be neatly packaged into distinct boxes. For example, unemployment is an important indicator of economic activity; yet it is known that changes in unemployment rates affect individuals and their families through increased stress which may lead to higher incidence of alcoholism, family breakdown and higher suicide rates. Similarly, poverty has an important economic dimension, but also social implications through the degree of social deprivation which it may generate.

Recently, to the recognition that economic growth does not necessarily lead to human development has been added a new awareness that economic growth is increasingly fueled by human capital. Old indicators are being modified and new ones are being developed to take into consideration the reality of the sources of strength of the new economy. Table 1 shows five sets of indicators selected from the United Nations' (UN) indicators of human capital, the World Bank's "competitiveness indicators", the United Nations' human development indicators (Human Development Report 1999), the Organization for Economic Co-operation and Development's (OECD, 1996) "social indicators", and the "indicators of social health" developed by the Fordham Institute for Innovation on Social Policy (Miringoff 1995). 
Table 1. Selected Economic and Social Indicators

\begin{tabular}{|c|c|c|c|c|c|}
\hline Indicators & $\begin{array}{c}\text { World } \\
\text { Bank } \\
\text { Capital } \\
\text { Indicators }\end{array}$ & $\begin{array}{c}\text { UN } \\
\text { Human } \\
\text { Capital } \\
\text { Indicators }\end{array}$ & $\begin{array}{c}\text { UN Human } \\
\text { Development } \\
\text { Indicators }\end{array}$ & $\begin{array}{c}\text { OECD } \\
\text { Social } \\
\text { Indicators }\end{array}$ & $\begin{array}{c}\text { Fordham } \\
\text { Index of } \\
\text { Social } \\
\text { Health }\end{array}$ \\
\hline Literacy Rate & $\mathrm{X}$ & $\mathrm{X}$ & $\mathrm{X}$ & & \\
\hline $\begin{array}{c}\text { Enrollment in } \\
\text { Primary and } \\
\text { Tertiary } \\
\text { Education }\end{array}$ & $\mathrm{X}$ & & & & \\
\hline $\begin{array}{c}\text { Life Expectancy } \\
\text { at Birth }\end{array}$ & & $\mathrm{X}$ & & $\mathrm{X}$ & \\
\hline $\begin{array}{c}\text { Mean Years of } \\
\text { Schooling }\end{array}$ & & $\mathrm{X}$ & & & \\
\hline $\begin{array}{c}\text { Scientists and } \\
\text { Technicians }\end{array}$ & $\mathrm{X}$ & $\mathrm{X}$ & & & \\
\hline $\begin{array}{c}\text { R \& D Scientists } \\
\text { and Technicians }\end{array}$ & $\mathrm{X}$ & $\mathrm{X}$ & & $\mathrm{X}$ & \\
\hline $\begin{array}{c}\text { Tertiary } \\
\text { Graduates }\end{array}$ & & $\mathrm{X}$ & & & $\mathrm{X}$ \\
\hline Science Graduates & $\mathrm{X}$ & $\mathrm{X}$ & & & \\
\hline $\begin{array}{c}\text { R \& D } \\
\text { Expenditures }\end{array}$ & $\mathrm{X}$ & & & & $\mathrm{X}$ \\
\hline Patent Granted & $\mathrm{X}$ & & & & \\
\hline $\begin{array}{c}\text { Real GDP per } \\
\text { Capita }\end{array}$ & & & & & \\
\hline $\begin{array}{c}\text { Unemployment } \\
\text { Rate }\end{array}$ & & & & & \\
\hline $\begin{array}{c}\text { Average Working } \\
\text { Hours }\end{array}$ & & & & & \\
\hline Infant Mortality & & & & & \\
\hline $\begin{array}{c}\text { Poverty } \\
\text { Inigh-School } \\
\text { Drop-out }\end{array}$ & & & & & \\
\hline $\begin{array}{c}\text { Health Insurance } \\
\text { Coverage }\end{array}$ & & & & & \\
\hline $\begin{array}{c}\text { Food -Stamp } \\
\text { Coverage }\end{array}$ & & & & & \\
\hline $\begin{array}{c}\text { Distribution of } \\
\text { Income }\end{array}$ & & & & & \\
\hline
\end{tabular}

The first two sets focus explicitly on human capital acquisition. While the indicators of human capital used by the World Bank and the United Nations have a number of elements in common, the list used by the World Bank is more extensive and includes elements that affect the degree of competitiveness of a country such as R \& D expenditures. In both cases, however, the indicators explicitly assigned to human capital involve a narrow definition of this term as 
they are largely confined to the utilization of formal learning institutions and learning achievements.

The remaining three sets of indicators focus on the social aspects of human development. In some cases, the indicators cover a wide spectrum of human activity, as in the case of the UN Human Development Index (column 3) and the OECD list of social indicators (column 4). In other cases, there are more restricted in coverage, as in the Fordham Index of Social Health (column 5).

As in the case of indicators of general economic activity, human capital is viewed largely in isolation from its human environment. It has been singled out lately because of the recognition of its importance in the process of economic growth within a knowledge-based economy. Because of this growth-oriented focus, human capital is defined in a very narrow manner being confined to acquisition only.

However, human capital formation is multi-faceted and involves a variety of activities from health to immigration. The narrow definition may miss some crucial aspects of human capital and serve as a poor guide for the development of public policy. Ruggeri and Yu (2000) introduced a broader definition of human capital that includes four components: (a) potential, (b) acquisition, (c) availability, and (d) effectiveness. ${ }^{1}$

We argue in this paper that human capital has become sufficiently important that it requires its own set of indicators for each of the four components. Following this broad definition, we set up selection criteria and present a suggested list of indicators of human capital for each dimension. We show that these new sets of indicators include elements of both economic and social indicators. In addition, we distinguish between the outcome indicators that represent the results of human capital formation and the process indicators that determine the results.

This paper adds to the existing literature in three areas. First, the existing literature focusing on a narrow definition of human capital misses crucial aspects of human capital; the proposed research provides a broader framework to evaluate both economic and social policies on human capital. Second, a comprehensive list of indicators is developed for the purpose of monitoring economic growth and making comparisons across countries or regions. Finally, we identify policy channels through which human capital formation can be strengthened in the new knowledge-based economy.

\section{Indicators of Human and Social Capital}

Human and social capital indicators are instruments which use social and economic data to represent developments in human capital formation and the realization of social and economic goals via human capital. In developing indicators of human capital, we follow the broad definition suggested by Ruggeri and $\mathrm{Yu}$ (2000) which includes four components: (1) potential, (2) acquisition, (3) availability and (4) effectiveness. For each dimension, we use

\footnotetext{
${ }^{1}$ These four components are briefly discussed in the next section.
} 
four major selection criteria: (a) differentiation between process and outcome, (b) cause and effect relationship, (c) statistical independence and (d) data availability.

Process and Outcome: One of the main purposes for developing human capital indicators is to facilitate the quantitative evaluation of how private processes and public policies affect the production, acquisition and utilization of human capital. Therefore, as a first step, it is important to clearly separate the indicators that measure the results within each dimension of human capital from the indicators that identify the factors affecting those outcomes. We call the latter "process" indicators and the former "outcome" indicators.

Cause and Effect: Since the purpose of the separation of indicators according to the first criterion is to identify the links between determining factors and results, process and outcome indicators must be chosen with a view to establish, at a conceptual level, causal relationships between process and outcome indicators. The selected indicators will allow econometric testing of the strength of such relationships.

Statistical Independence: As shown by the list of selected human development and/or social indicators in the previous section, the number of potential candidates for human capital indicators is quite large. Even a superficial inspection shows that many of those indicators are likely to be highly correlated. Using a large number of correlated indicators within each of the two major categories of indicators will add unnecessary complications without providing new information. We selected only a few major indicators in each category based on the expected absence of co-variance among the selected items.

Data Availability: In the selection process we start with the indicators that best fit the above three criteria. We recognize, however, that in some cases the relevant data may not be readily available. In those cases we substitute the closest proxy for each reliable data available.

We now apply the aforementioned criteria to select the indicators for each of the four dimensions of human capital.

\section{Potential}

The potential dimension traces human capital to its primary source. It highlights two fundamental aspects of human capital; (a) the production of the pool of agents who may acquire human capital and (b) the conditions and institutions that may affect the ability of those agents to acquire human capital in the future. The major characteristic of both aspects of potential human capital is that all relevant decisions are made by individuals other than the carriers of potential human capital.

The first step in the selection of indicators of potential human is the choice of the age cut-off. A strict definition of potential would limit this component of human capital to the new-born and their parents. One may argue, however, that this component should be viewed in a broader sense and include children of pre-school age. During this period the potential carriers of human capital are totally dependent on their care-givers and their learning experience is largely 
confined to fundamental survival and social skills. We have opted for this broader approach in our selection of the indicators of potential human capital by including in this dimension, children of age 0-5. In our selection we separate the production component - the production of the pool of agents who may acquire human capital from the nurturing component - the conditionals and institutions that my affect the ability of those agents to acquire human capital in the future.

First, on the production side the decision to procreate appears to be a strictly private choice despite the large positive spill-overs of human capital. This private decision involves a complex set of economic, social, cultural and biological factors. The major economic determining factor is the cost of raising a child to a state of adult independence (e.g., age 18). Four major features of the cost of having and raising children can be identified. First, child-raising involves a commitment over a long period of time. Second, these expenditures are quite large, even on an annual basis. Third, child-rearing increases the cost of earning income. Finally, the cost of child-rearing may be positively related to the parents' income as a child is expected to share his/her parents' standard of living. Because each child requires a large financial commitment, the decision to procreate does not involve marginal adjustments in the allocation of the family budget. Therefore, financial incentives which represent a small portion of the total cost of raising a child are not likely to affect the procreation decision. This general conclusion is supported by empirical evidence on the effect of lump-sum grants to parents per child produced. Stronger impacts may be generated by indirect subsidies, such as free health care, free primary and secondary education, heavily subsidized post-secondary education, and programs that minimize the loss of earnings due to the production and nurturing of children.

For the nurturing component, empirical studies show that the early years of a child's life are crucial for his/her intellectual and emotional development. During this period the potential abilities received at birth may be enhanced or degraded. Nurturing is a social activity, carried directly by the parents or closest relatives but greatly influenced by the structure of social institutions and by public policies. Although the love that parents offer is not constrained by economic factors, the child development environment that they can offer is. Low educational attainment by the parents may affect their educational goals for their children while the lack of financial resources will prevent them from providing stimulating activities or even the quality of nutrition required for steady intellectual development. The degradation of human potential in the early years of a child's life has long-term implications because it will be compounded by lower achievement during the period of formal education.

Based on the proceeding discussions and the established criteria, we selected three outcome indicators and five process indicators for the potential human capital dimension. As shown in Table 2, the first two outcome indicators provide information on the quantity of human capital carriers. This amount is determined by proportion of children of age $0-5$ as a percent of the population and their probability of survival as measured by their age-specific 
mortality rate. The third outcome indicator -- child development at age 5 -- is a quality measure of potential human capital since age five is the final year for the potential human capital dimension. Among the process indicators are: cost of raising a child to the age of 18; poverty rate among families with children of age 0-5; public expenditures on child development; labour market programs; and health care programs for mother and child. The first one has been identified as a key economic determinant of having children and hence is expected to affect the quantity of potential human capital. The second one serves to capture a variety of variables that may affect the quality of these potential human capital carriers. The poverty rate represents all the economic and social conditions that influence the ability and willingness of these children to acquire human capital in future years. The remaining three process indicators are indicators of various social programs aimed at enhancing largely the quality of potential human capital. Public expenditures on child development are a direct predictor of early childhood development due to the importance of early childhood education in successful human capital acquisition in future years. Labour market programs such as maternity leaves, benefits such as Employment Insurance and Canada Pension Plan may affect both the quantity and quality of potential capital in this dimension. Similarly, health care programs may also affect the quantity and quality of potential human capital. Finally, parents' education level is included as a factor that determines the quality of potential human capital.

Table 2. Indicators of Potential Human and Social Capital

\begin{tabular}{|l|l|}
\hline \multicolumn{1}{|c|}{ Process } & \multicolumn{1}{|c|}{ Outcome } \\
\hline $\begin{array}{l}\text { Poverty rate of families with } \\
\text { children aged 0-5 }\end{array}$ & $\bullet \begin{array}{l}\text { Children aged 0-5 as \% of the } \\
\text { population } \\
\text { - } \begin{array}{l}\text { Cost of raising a child to age 18 } \\
\text { - Public spending per child on } \\
\text { children aged 0-5 }\end{array}\end{array}$ \\
$\begin{array}{l}\text { Labour market programs } \\
\text { Indicator of child development at } \\
\text { age 5 }\end{array}$ \\
$\begin{array}{l}\text { Health care programs for mother } \\
\text { Parents' education level }\end{array}$ & \\
\hline
\end{tabular}

\section{Acquired}

This dimension of human capital involves a transition from external to personal choice and can be divided into two stages. The first stage is the continuation of the potential dimension and involves the period when choices are to a large extent not made by the agent. It can be identified with elementary and secondary education. The second stage involves the rest of the formal learning experience where the agent can make choices with respect to attendance and type of program. This second stage is the component of human capital which is generally incorporated in models of endogenous growth.

For this dimension, we selected five outcome indicators shown in Table 3. The first, the literacy rate, is a broad indicator aimed at capturing basic 
educational attainment. The inability to read is a serious handicap in performing even the simplest tasks in market employment. A low literacy rate would also indicate a low preference for human capital acquisition among the population. The remaining four outcome indicators are focused on selected groups. The proportion of grade 12 students who actually graduate provides information on the strength of desire to learn; it serves as an indicator of the preferences for future learning. The educational attainment of the population aged 25-64 serves as an indicator of the desire to acquire human capital by agents who can make free choices about human capital acquisition. The percentage of graduate with science degrees is a measure of the acquired human capital in demand by the "knowledge" sector of the economy. Finally, adult participation in education and training provides information on the pace of skill upgrading necessary to avoid skill depreciation in an age of rapid technological change.

On the process side we selected also five indicators, two for the first stage and three for the second stage of the acquisition dimension. The teacher-pupil ratio in primary and secondary schools serves as an indicator of the quality of compulsory education, on the assumption that greater personal attention to students in their formative years stimulates their interest in learning. The educational attainment of teachers provides an indicator of the quality of instruction at the primary and secondary level.

Table 3. Indicators of Acquired Human and Social Capital

\begin{tabular}{|c|c|}
\hline Process & Outcome \\
\hline $\begin{array}{ll}\text { - } & \text { Educational attainment of } \\
\text { teachers } \\
\text { - } & \text { Teacher-pupil ratio in elementary } \\
\text { and secondary schools } \\
\text { - } & \text { Annual rate of return to education } \\
\text { - } & \text { Spending on public labour market } \\
& \text { programs } \\
\text { - } & \text { Spending by enterprises on } \\
\text { training }\end{array}$ & 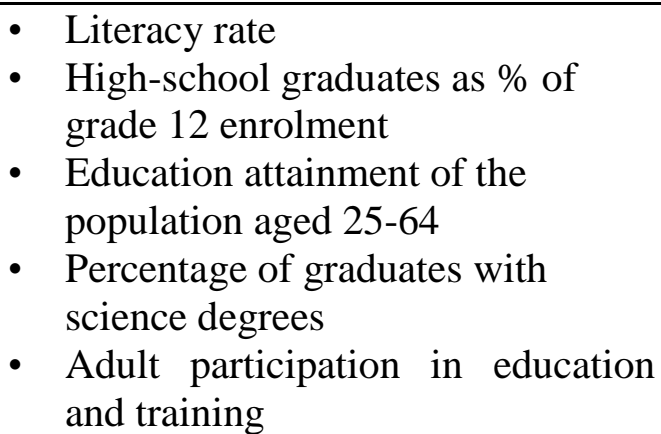 \\
\hline
\end{tabular}

For all other learning programs where the individual can make a free choice, the major process indicator is the comparison between the cost of acquiring additional human capital and the expected return from the additional investment in human capital. Called the annual rate of return to education, this complex indicator depends on the cost of delivering a program, the level of public subsidization, the existing wage structure and the expected future changes in the wage structure. Finally, we included spending on public labour market programs and spending by enterprises on training to measure the effects of training expenditures on workplace skills. 


\section{Availability}

The first two dimensions measure the stock of human capital that is generated in a country, part of which may be used immediately (acquired) and part of which may become useable in the future (potential). What matters for economic growth, however, is the amount and quality of human capital that is available for productive purposes. In a global economy characterized by increased mobility of people as well as goods, human capital that has been generated within a country may not be totally available for use in that country if it is depleted by selective out-migration known as the "brain drain." By the same token, the amount of human capital generated domestically may be augmented by selected immigration, which may be called "brain gain." Even when, on the aggregate, immigration cancels out emigration, there is no guarantee that the net effect on human capital is neutral. Even in the extreme case where human capital on balance is left unchanged by international labour mobility, it is still useful to identify the inflow and outflow separately because each side of the flow is related to important policy instruments. Identifying the factors that affect these flows helps clarify the channels through which public policy affects economic growth through changes in the availability of human capital.

Table 4. Indicators of Available Human and Social Capital

\begin{tabular}{|l|ll|}
\hline \multicolumn{1}{|c|}{ Process } & \multicolumn{1}{c|}{ Outcome } \\
\hline$\bullet \quad$ Wage differential & $\bullet$ & Immigration of individuals aged 0- \\
& 19
\end{tabular}

Table 4 shows eight selected indicators for this dimension. There are five outcome indicators. The first four indicators measure selected aspects of immigration and emigration. Since our focus is on human capital we have selected only individuals that represent potential or acquired human capital. The last one captures the loss of human capital due to the apprehension of individuals engaged in criminal activities. This loss is particularly significant because the majority of those incarcerated at any one time is composed largely of young people.

On the process side we selected three indicators which may capture the complex factors that affect the availability of human capital. The first two try to capture the main factors that may be affecting the emigration of highlyskilled Canadians to the U.S. The last one applies largely to immigration from 
countries other than the U.S. It will capture the elements of immigration policy that affect the immigration of individuals 0-64, particularly those with technical, scientific and entrepreneurial skills.

\section{Effectiveness}

So far we have looked at the supply side of human capital. In order for human capital to be transformed into productive activity it must be employed and in an effective manner. What society ultimately gets out of human capital depends on its utilization and performance. These two components form the final dimension of human capital used in our classification of human capital indicators.

Table 5 shows our suggested list of indicators for this dimension. For outcome indicators, the first is the overall unemployment rate and is used as a measure of labour utilization. The second indicator focuses on that portion of the labour force with upper-secondary and tertiary qualifications. Relatively higher rates of unemployment for this component of the labour force would point to the inability of the economy to fully exploit the opportunities of the knowledge-based economy. The next outcome indicator provides some information of the performance of human capital. A high degree of absenteeism indicates workers' dissatisfaction and is likely to lead to lower performance. Absenteeism may also reflect under-utilization of human capital due to other factors such as illness, personal and family problems and the like. The final outcome indicator is a quality measure of labour productivity because more satisfied workers are more likely to fully utilize their human capital.

The first process indicator provides information on what may be called the state of health of the labour market. When employer-employee relations are harmonious and there is a high degree of job satisfaction, work stoppages due to strikes are minimized and worker absenteeism is low. Low absenteeism may also reflect a healthier population which is the result of a good health care system and a working environment that not put excessive stress on the physical and emotional conditions of workers. We selected the health status of the population to capture this possible effect between health and performance. The final process indicator is related to employment/unemployment of the educated. The share of private and public spending on research and development affects directly the demand for human capital. A positive attitude by firms and governments towards research and development also provides an environment conducive to creativity and higher performance. Such a climate may also encourage the acquisition of new capital, thus affecting another dimension, by improving the employment expectations of would be scientists. 
Table 5. Indicators of Effective Human and Social Capital

\begin{tabular}{|c|c|}
\hline Process & Outcome \\
\hline $\begin{array}{l}\text { Employers' attitudes towards } \\
\text { employees } \\
\text { - Health status of the population } \\
\text { Proportion of GDP spent on } \\
\text { research and development }\end{array}$ & $\begin{array}{l}\text { - Unemployment rate } \\
\text { - } 25-64 \text { with upper-secondary and } \\
\text { tertiary level qualification } \\
\text { - Person-days of absenteeism as \% } \\
\text { of total employment (in person- } \\
\text { days) } \\
\text { - Index of job satisfaction }\end{array}$ \\
\hline
\end{tabular}

\section{Conclusions}

Human and Social capital is increasingly becoming the major driving force behind productivity and economic growth. To grow and expand per capita output and consumption, thus improving living standards, a country must increase its productivity. The need for productivity growth becomes stronger in a globalized economy where countries compete both for resources and markets. As productivity growth depends to an increasing degree on the development and application of new technology, public policy must be geared to the growth of human capital, the enhancement of its quality and the effectiveness of its utilization.

In order to better understand the impact of different policies on human capital, it is important that we have a clear idea of its dimensions, the process by which it is created and what affects its use and its performance. In this paper we use a broad definition of human and social capital developed by Ruggeri and $\mathrm{Yu}(2000)$ which includes four dimensions: (a) potential, (b) acquisition, (c) availability and (c) effectiveness. This categorization serves two main purposes. First, it helps identify which policies affect human capital and at which stage. Second, it helps identify the links through which human capital moves from one stage to another. This categorization also helps develop a research agenda that takes a comprehensive look at a variety of implications of human capital and social capital.

For each dimension of the human and social capital, we developed a set of process and outcome indicators. While the outcome indicators directly impact the quantity or quality of human capital in various stages, the process indicators influence the outcome indicators. Since a country's growth depends on its productivity which is determined by the quantity and quality of its human capital, many of the selected indicators will indirectly impact the growth via human capital. As examples, indicators such as health, education, immigration policy, spending on R \& D etc. will determine a country's human which ultimately will determine its growth. In short, the link between the identified indicators and economic growth policies can be described by the standard production function: $\mathrm{GDP}=\mathrm{f}(\mathrm{L}, \mathrm{K})$, where $\mathrm{L}$ represents the quantity 
and quality of a country's human capital. All indicators identified in this paper will change $\mathrm{L}$ will in turn changes GDP and hence the growth rate.

\section{References}

Miringoff ML (1995) Toward a national standard of social health: the need for progress in social indicators. American Journal of the Orthopsychiatry Association 65(4): 465.

OECD (1996) Measuring what People Know: Human Capital Accounting for the Knowledge Economy. Paris: Organisation for Economic Co-operation and Development (OECD).

Ruggeri GC, Yu W (2000) On the dimensions of human capital: an analytical framework. UNB Department of Economics Working Papers 2000 Series.

Smith A (1776) The wealth of nations, Book II, On the Nature, Accumulation, and Employment of Stock, London: Strahan, W. and Cadell, W.

United Nations (1999) Human Development Report 1999. Published for the United Nations Development Programme (UNDP), New York: Oxford University Press. 